\title{
Targeting the insulin growth factor-1 receptor with fluorescent antibodies enables high resolution imaging of human pancreatic cancer in orthotopic mouse models
}

\author{
Jeong Youp Park ${ }^{1,2,3}$, Jin Young Lee ${ }^{3}$, Yong Zhang ${ }^{2}$, Robert M. Hoffman ${ }^{1,2}$, Michael \\ Bouvet $^{1,4}$ \\ ${ }^{1}$ Department of Surgery, University of California San Diego, San Diego, CA, USA \\ ${ }^{2}$ AntiCancer, Inc., San Diego, CA, USA \\ ${ }^{3}$ Department of Internal Medicine, Yonsei University College of Medicine, Seoul, Korea \\ ${ }^{4}$ Surgical Service, VA San Diego Healthcare System, San Diego, CA, USA \\ Correspondence to: Michael Bouvet, email: mbouvet@ucsd.edu
}

Keywords: insulin-like growth factor-1 receptor (IGF-1R), fluorescent antibody, orthotopic nude mice, imaging, pancreatic cancer Received: December 03, $2015 \quad$ Accepted: February 11,2016 Published: February 22, 2016

\section{ABSTRACT}

The goal of the present study was to determine whether insulin-like growth factor-1 receptor (IGF-1R) antibodies, conjugated with bright fluorophores, could enable visualization of pancreatic cancer in orthotopic nude mouse models. IGF-1R antibody (clone 24-31) was conjugated with $550 \mathrm{~nm}$ or $650 \mathrm{~nm}$ fluorophores. Western blotting confirmed the expression of IGF-1R in Panc-1, BXPC3, and MIAPaCa-2 human pancreatic cancer cell lines. Labeling with fluorophore-conjugated IGF-1R antibody demonstrated fluorescent foci on the membrane of the pancreatic cancer cells. Subcutaneous Panc-1, BxPC-3, and MIA PaCa-2 tumors became fluorescent after intravenous administration of fluorescent IGF-1R antibodies. Orthotopicallytransplanted BxPC-3 tumors became fluorescent with the conjugated IGF-1R antibodies, and were easily visible with intravital imaging. Gross and microscopic ex vivo imaging of resected pancreatic tumor and normal pancreas confirmed that fluorescence indeed came from the membrane of cancer cells, and it was stronger from the tumor than the normal tissue. The present study demonstrates that fluorophoreconjugated IGF-1R antibodies can visualize pancreatic cancer and it can be used with various imaging devices such as endoscopy and laparoscopy for diagnosis and fluorescence-guided surgery.

\section{INTRODUCTION}

For pancreatic cancer, CA19-9 is the only biomarker being used in the clinic despite many needs for others [1-3]. Several cell surface biomarkers for molecular imaging have been reported in pancreatic cancer [4-6]. We previously demonstrated that CEA, CA19-9, and MUC1 could be targeted in pancreatic cancer with specific fluorescent antibodies, enabling imaging in orthotopic mouse models [7-9].

Type I insulin-like growth factor receptor (IGF-1R) is a potential diagnostic and therapeutic biomarker of several cancers [10]. It is a transmembrane tyrosine kinase receptor comprising two $\alpha$ and two $\beta$ chains. IGF-1R is the major receptor for IGF-I and IGF-II, and importantly expressed in $97.6 \%$ of pancreatic cancers [11]. There is also a report that the expression of IGF-1R in pancreatic cancer is higher than in normal pancreas [12]. IGF-1R plays important roles in cell proliferation, apoptosis, angiogenesis, and tumor invasion [13-15]. In addition, a few studies have shown fluorescence imaging using IGF-1R targeting on tumors is possible, and its potential clinical usefulness has been discussed [16]. In the present study, we demonstrate that fluorescent anti-IGF-1R antibodies target pancreatic cancer in orthotopic mouse models enabling non-invasive imaging and high resolution intra-vital imaging of the tumor. 


\section{RESULTS}

\section{Expression of IGF-1R in pancreatic cancer cells in vitro}

Western blotting showed Panc-1, BxPC-3, and MIA PaCa-2 pancreatic cancer cell lines expressed IGF1R (Figure 1A). After incubation with the fluorophoreconjugated IGF-1R antibody, without permeation, multiple fluorescent foci were visualized on the membrane of Panc1 and BxPC-3 cells under fluorescence microscopy (Figure 1B) confirming the expression of IGF-1R on cancer cells.

\section{Targeting subcutaneous pancreatic tumors in nude mice with fluorescent IGF-1R antibodies}

When Panc-1, BxPC-3, and MIA PaCa-2 subcutaneous tumors reached approximately $10 \mathrm{~mm}$ in diameter, a single $30 \mu \mathrm{g}$ dose of DyLight 650-conjugated anti-IGF-1R (clone 24-31) in $150 \mu$ l PBS was injected via the tail vein. The mice were imaged by both brightfield and fluorescence illumination using the variable magnification OV100 48 hours after the injection. All the subcutaneous tumors had stronger fluorescence compared to background (Figure 2).

\section{Targeting orthotopic pancreatic tumors in nude mice with fluorescent IGF-1R antibodies}

Mice with BxPC-3 tumors, orthotopically-implanted in the tail of the pancreas, were injected with DyLight 650-conjugated anti-IGF-1R (clone 24-31) antibody. A single $30 \mu \mathrm{g}$ dose in $150 \mu \mathrm{l}$ PBS was injected via the tail vein 14 days after tumor implantation. After opening the abdomen, the OV100 detected the bright tumor fluorescence (Figure 3). Minimal fluorescence was also observed at the skin, bladder, and intestinal contents which had lower intensity than the tumor.

\section{Ex-vivo microscopic imaging of orthotopic pancreatic tumors with fluorescent IGF-1R antibodies}

Mice with BxPC-3 tumors, orthotopically-implanted in the tail of the pancreas were injected with a single 10 $\mu \mathrm{g}$ dose of DyLight 650-conjugated anti-IGF-1R (clone 24-31) in $150 \mu \mathrm{l}$ PBS dose via the tail vein 14 days after tumor implantation. After opening the abdomen, the tumor, normal pancreas and spleen were resected as a block. They were observed under the IV-100 scanning laser microscope with a microprobe objective lens (1.3 $\mathrm{mm}$ diameter) (Figure 4A). A strong fluorescence signal on the surface of cancer cells was detected at high resolution with only minimal fluorescence in the interstitium of the normal pancreas (Figure 4B). Hematoxylin \& eosin staining of tissue samples and immuno fluorescence staining confirmed the expression of IGF-1R in the pancreatic cancer tissues (Figure 4C).

\section{DISCUSSION}

In the present study, we used a microprobe objective lens for ex vivo imaging, which had x20 magnification power and a diameter of $1.3 \mathrm{~mm}$. It resembles a confocal laser endomicroscope which has a diameter of $0.8 \sim$ $2.8 \mathrm{~mm}$ [17]. Our results suggest microscopic fluorescence imaging using such a device could allow detection of IGF$1 \mathrm{R}$ in vivo without tissue sampling.

Recent progress in fluorescence imaging and devices has allowed finer visualization of not only hollow organs such as the esophagus, stomach and
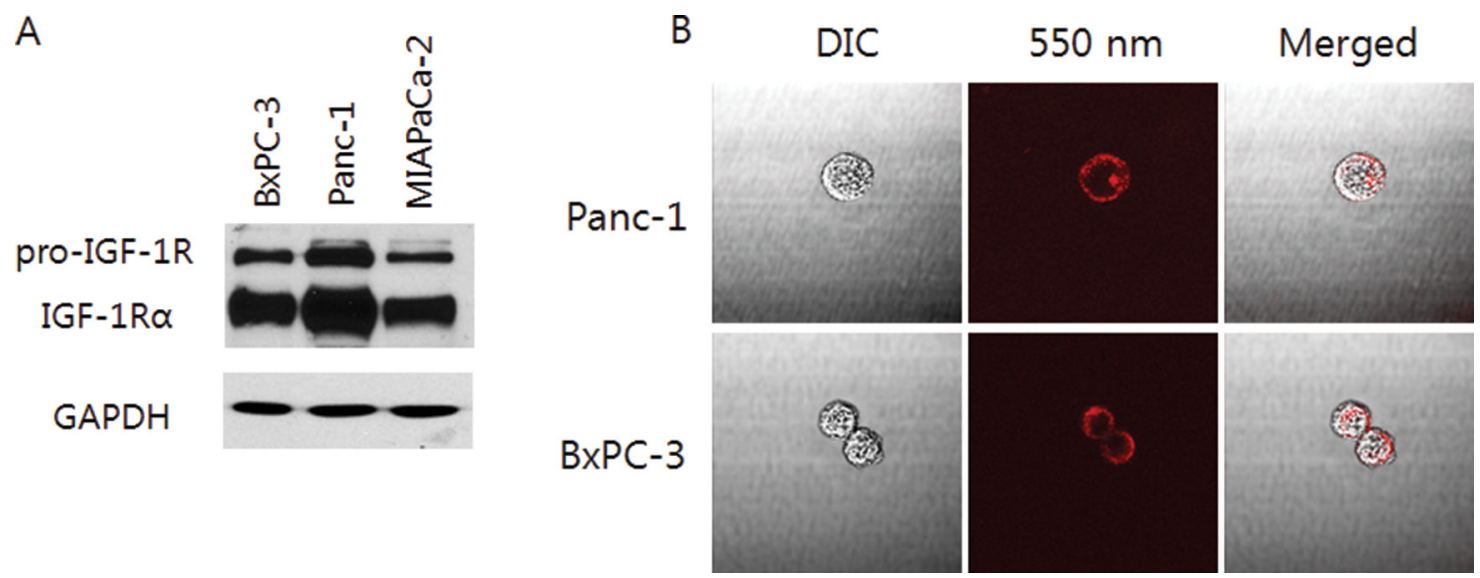

Figure 1: Characterization of pancreatic cancer cell lines. A. Western blot analysis shows pro-IGF-1R and IGF-1R $\alpha$ expression at 200 and $130 \mathrm{kDa}$ in pancreatic cancer cell lines, respectively (Panc-1, BxPC-3, MIA PaCa-2). B. Labeling of live Panc-1 and BxPC-3 cells with $550 \mathrm{~nm}$ fluorophore-conjugated antibodies shows multiple fluorescent foci on the cell membrane. Merged images were created with corresponding DIC (differential interference contrast) images (x60 water immersion objective with the FV1000 confocal microscope, using the $559 \mathrm{~nm}$ laser). 
colon, but also intra-abdominal solid organs such as the liver, spleen, and pancreas [18-21]. Fluorescence imaging for pancreatic cancer can be especially useful since it can reduce the time and errors associated with tissue biopsy. Since IGF-1R is very frequently expressed in pancreatic cancer, and its expression is stronger than in the normal pancreas $[11,12]$, detecting IGF-1R can be used for diagnosis purposes. We have previously shown

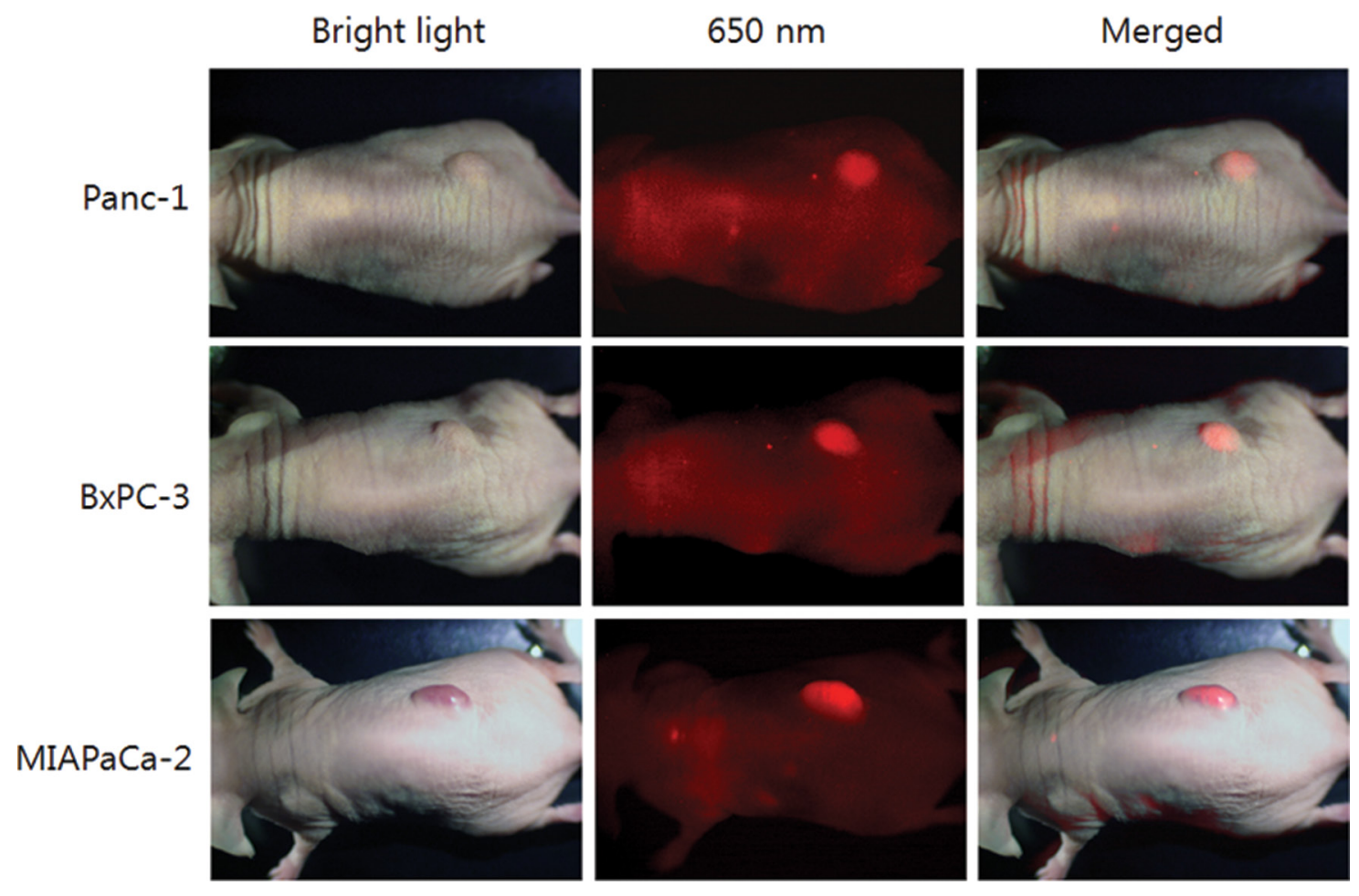

Figure 2: Imaging of $650 \mathrm{~nm}$ fluorophore-conjugated IGF-1R antibody targeted subcutaneous pancreatic tumors in vivo. The mouse is imaged under both white light and fluorescence illumination with the OV100. The intensity of fluorescence from the Panc-1, BxPC-3, MIA PaCa-2 subcutaneous tumors are stronger than background.

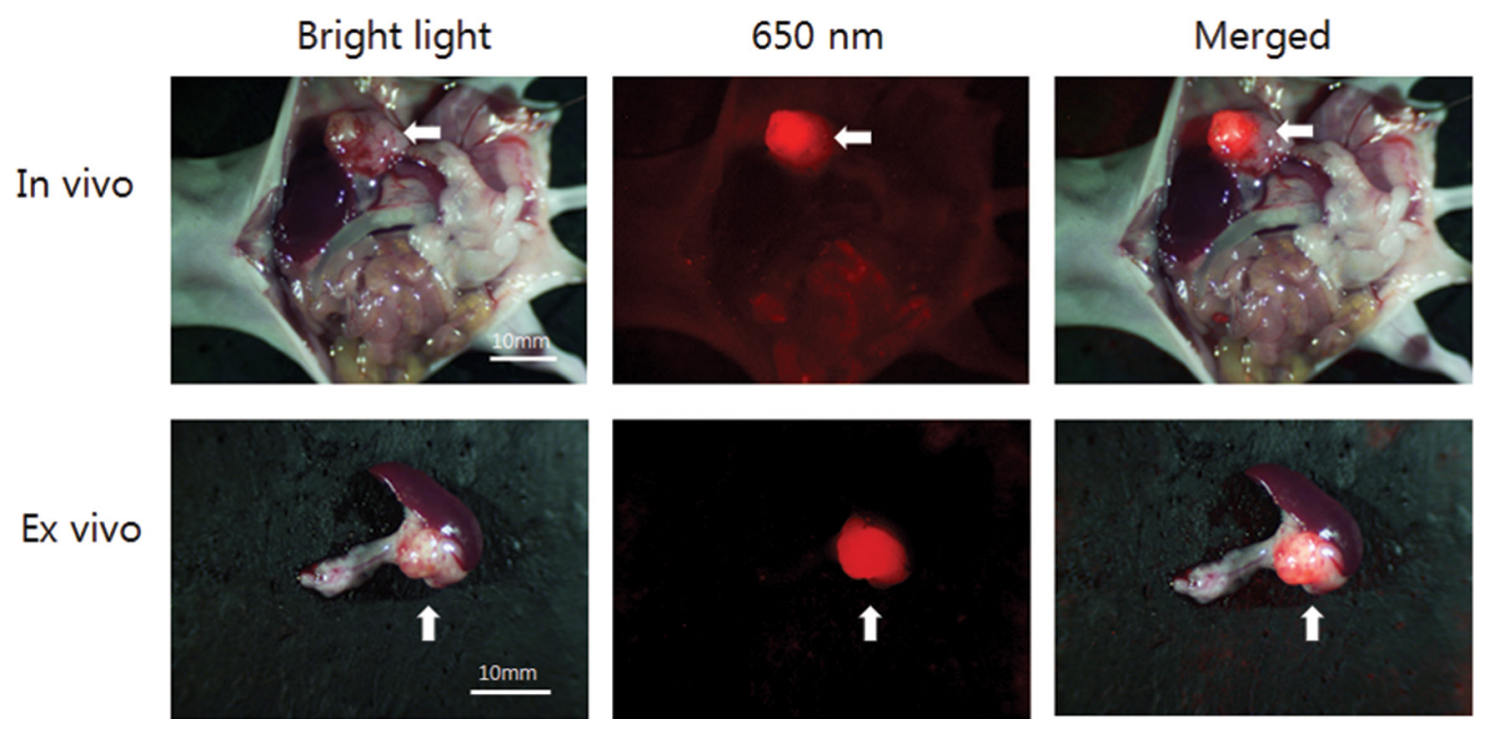

Figure 3: Imaging of fluorophore-conjugated IGF-1R antibody targeted orthotopically-transplanted BxPC3 pancreatic tumors in vivo and ex vivo. Fluorescence from orthotopically-transplanted pancreatic tumors in the tail of the pancreas was detected in vivo with the OV100 after abdominal laparotomy. Weak fluorescence was also detected from the skin and, bladder and intestinal contents, but at much lower intensity than the tumor. Also, fluorescence from the resected tumor was detected at high resolution with the IV100, but not from the normal pancreas. White arrows indicate pancreatic tumor. 
that fluorescence guided surgery (FGS) can increase survival or effect cures in pancreatic cancer mouse models [22]. Targeting IFG-1R in pancreatic cancer with fluorophore conjugated antibodies may also be useful for fluorescence-guided surgery.

IGF-1R fluorescent antibody binding to pancreatic cancer cells and tumors is specific, as shown by Western blotting of IGF-1R binding to the cancer cell membranes (Figure 1) by the much greater antibody-derived fluorescence, compared to non-specific autofluorescence, and in orthotopic as well as subcutaneous tumors seen by both microscopic as well as endoscopic-like imaging devices, and by histological experiments which showed that the antibody specifically binds to tumor tissue (Figure 4).

The present study is a major advance over previous studies [16, 23] on binding of IDG-1R fluorescent antibodies to pancreatic cancer as our model is orthotopic and therefore clinically relevant, including the fact that an endoscope-like device can detect the fluorescent IGF-1R antibody bound to tumor tissue.

With regard to the choice of fluorophore to conjugate to IGF-1R antibodies, we used DyLight 650 and 550 dyes because our previous studies demonstrated that these longer-wavelength dyes had increased depth of penetration and ability to detect the smallest tumor deposits and provided the highest tumor-background ratios (TBRs), resistance to hemoglobin quenching, and specificity compared to shorter wavelength dyes [24]. Other fluorophores may be useful in terms of colors and chemistry as outlined by Kobayashi et al $[25,26]$.

The tumor-targeting technology described in the present report can be used along with previously developed tumor-targeting strategies [27-32].

\section{MATERIALS AND METHODS}

\section{Pancreatic cancer cell lines}

The human pancreatic cancer cell lines BxPC-3 [33] and Panc-1 [34] MIA PaCa-2 were maintained in RPMI 1640 medium and DMEM supplemented with 10\% fetal bovine serum (Hyclone, Logan, UT), and penicillin/ streptomycin (Gibco-BRL, Carlsbad, CA). All cells were cultured at $37^{\circ} \mathrm{C}$ in a $5 \% \mathrm{CO}_{2}$ incubator.

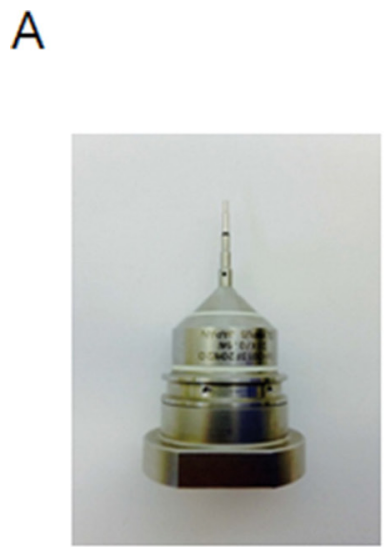

\section{B}
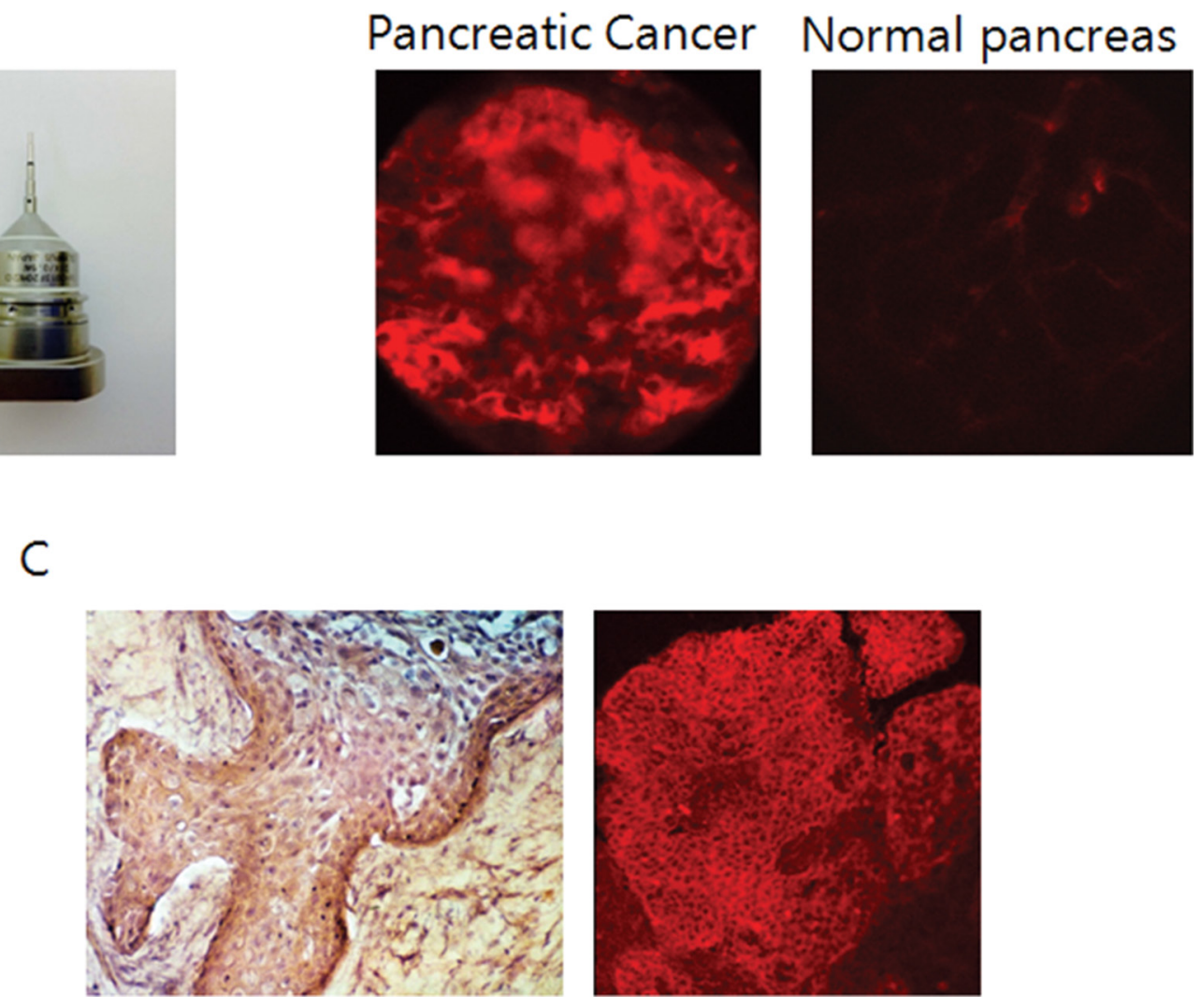

Figure 4: Ex-vivo microscopic imaging of an orthotopic pancreatic tumor labeled with fluorescent anti-IGF-1R antibody. A. Microprobe lens (x20) used with the IV-100. B. Ex vivo imaging done with the IV-100 visualized fluorescence from the surface of BxPC-3 cancer cells in the orthotopic tumor with anti-IGF-1R conjugated to a $650 \mathrm{~nm}$ DyLight dye. C. H \& E and fluorescence staining of a tissue sample (x200) confirm the specific expression of IGF-1R on the surface of the pancreatic cancer cells. 


\section{Mice}

Athymic nu/nu nude mice (AntiCancer Inc., San Diego, CA), 4-6 weeks old, were used in the study. Mice were kept in a barrier facility under HEPA filtration and fed with an autoclaved laboratory rodent diet. All mouse surgical procedures and imaging were performed after anesthetized by intramuscular injection of $50 \%$ ketamine, $38 \%$ xylazine, and $12 \%$ acepromazine maleate (0.02 $\mathrm{ml})$. Animals received buprenorphine $(0.10 \mathrm{mg} / \mathrm{kg} \mathrm{ip})$ immediately prior to surgery and once a day over the next 3 days. The maximum tumor size allowed to grow was $2 \mathrm{~cm}$. The condition of the animals was monitored every day. $\mathrm{CO}_{2}$ inhalation was used for euthanasia. To ensure death following $\mathrm{CO}_{2}$ asphyxiation, cervical dislocation was performed. All animal studies were approved by AntiCancer, Inc.'s Institutional Animal Care and Use Committee (IACUC) in accordance with the principals and procedures outlined in the National Institute of Health Guide for the Care and Use of Animals under Assurance Number A3873-1.

\section{Antibody-dye conjugation}

Mouse monoclonal antibodies to IGF-1R (clone 24-31; Thermo Scientific, Rockford, IL, USA) were conjugated with DyLight 650 or 550 dyes (Thermo Scientific, Rockford, IL, USA) per manufacturer specifications, ensuring a minimum of at least 4:1 dye: protein ratio. Protein: dye concentrations were confirmed using a NanoDrop Spectrophotometer (Thermo Fisher Scientific, Waltham, Massachusetts) [24].

\section{Western blotting}

Cell lysates were extracted in lysis buffer containing $70 \mathrm{mM} \beta$-glycerophosphate, $0.6 \mathrm{mM}$ sodium orthovanadate, $2 \mathrm{mM} \mathrm{MgCl}, 1 \mathrm{mM}$ ethylene glycol tetraacetic acid, 1 mM DTT (Invitrogen, Grand Island, NY, USA), 0.5\% Triton-X100, $0.2 \mathrm{mM}$ phenylmethylsulfonyl fluoride, and $1 \%$ protease inhibitor cocktail (SigmaAldrich, St. Louis, MO, USA). Lysates were separated by sodium dodecylsulfate-polyacrylamide gel electrophoresis (SDS-PAGE) and transferred to polyvinylidene fluoride membranes (Millipore, Billerica, MA, USA). The membranes were blocked in $5 \%(\mathrm{w} / \mathrm{v})$ non-fat dry milk and probed with anti-IGF-1R (SC-712; Santa Cruz, Dallas, TX, USA). The immunoreactive proteins were visualized using the SuperSignal West Pico Chemiluminescent Substrate (Thermo Scientific).

\section{Labeling of live cells in vitro using fluorescent IGF-1R antibodies}

Panc- 1 and BxPC-3 cells $\left(2 \times 10^{5}\right)$ were cultured overnight. Anti-IGF-1R (clone 24-31) conjugated with DyLight 550 dye was diluted to $4 \mu \mathrm{g} / \mathrm{ml}$ in phosphate- buffered saline (PBS, Corning Cellgro, Manassas, VA). The culture medium from the cells was aspirated and the diluted antibody was added to the live cells. Cells were incubated with antibody for 1 hour at room temperature. The cells were washed gently 2 times with PBS after the antibody was aspirated. The cells were observed under an FV1000 confocal microscope (Olympus, Tokyo, Japan) with white light and $559 \mathrm{~nm}$ laser [35].

\section{Immunohistochemistry}

Anti-IGF-1R (clone 24-31) conjugated with DyLight 650 was used for staining tumor sections on slides. The slides were incubated with $10 \%$ normal donkey serum for 1 hour at room temperature, and incubated with the conjugated antibody at room temperature for 1 hour at a dilution of 1:100. Tissues were dried and observed with an IV-100 scanning laser microscope (Olympus, Tokyo, Japan) with a $633 \mathrm{~nm}$ laser [36]. Alternate slides from the same frozen tumor tissue were stained with hematoxylin and eosin and observed under light microscopy.

\section{Subcutaneous and orthotopic tumor mouse models}

To make subcutaneously-transplanted pancreatic tumor models, Panc-1, BxPC-3, and MIA PaCa-2 human pancreatic cancer cells $\left(2 \times 10^{6}\right)$ were injected subcutaneously into the flanks of nude mice. When the subcutaneous tumors grew between 10 and $20 \mathrm{~mm}$ in diameter, imaging of the subcutaneous tumor was performed. To make orthotopic-tumor mouse models, subcutaneous tumors were harvested and divided into small fragments which were implanted onto the tail of the pancreas using 8-0 nylon sutures in nude mice, as previously described [37-40].

\section{Whole body and intra-vital imaging}

In both subcutaneous and orthotopic tumor models, the mice were injected with the fluorescent antibody in the tail vein. After 48 hours, whole body non-invasive and intra-vital imaging of the subcutaneous and orthotopic tumors was performed using the OV100 Small Animal Imaging System (Olympus, Tokyo, Japan) [41]. The optimal dose for animal studies was decided by the amount of the conjugated antibody which produced images with the best TBR in the subcutaneous-tumor model.

\section{Intravital laser scanning microscope}

The IV-100 (Olympus) and the conjugated antibody were used to obtain microscopic fluorescence images of pancreatic tumors and the normal pancreas in the orthotopic mouse model. The IV-100 operates with four lasers $(488,561,633$, and $748 \mathrm{~nm}$ ) for excitation; three of which can be used simultaneously for imaging. Its 
microprobe lens has an external diameter of $1.3 \mathrm{~mm}$ and delivers high resolution images in the visible and nearinfrared spectrum. Due to its small size, it can be used to image abdominal organs through a small incision [42].

\section{Image analysis}

All images were analyzed using Image-J (National Institutes of Health, Bethesda, Maryland) before the process of images and compared. Image process was done with Adobe Photoshop CS3 (Adobe Systems Inc., San Jose, California).

\section{CONFLICTS OF INTEREST}

All the authors of this paper declare that they have no conflict of interest.

\section{GRANT SUPPORT}

This study was supported by grants from the National Cancer Institute CA142669 and CA132971 (to $\mathrm{MB}$ and AntiCancer, Inc.), and by a faculty research grant from Yonsei University College of Medicine 6-2015-0030 (to JYP).

\section{REFERENCES}

1. Fong ZV, Winter JM. Biomarkers in pancreatic cancer: diagnostic, prognostic, and predictive. Cancer journal. 2012; 18:530-538.

2. Winter JM, Yeo CJ, Brody JR. Diagnostic, prognostic, and predictive biomarkers in pancreatic cancer. Journal of surgical oncology. 2013; 107:15-22.

3. Lee KJ, Yi SW, Chung MJ, Park SW, Song SY, Chung JB, Park JY. Serum CA 19-9 and CEA levels as a prognostic factor in pancreatic adenocarcinoma. Yonsei medical journal. 2013; 54:643-649.

4. Yang L, Mao $\mathrm{H}$, Cao Z, Wang YA, Peng $\mathrm{X}$, Wang X, Sajja HK, Wang L, Duan H, Ni C, Staley CA, Wood WC, Gao X, Nie S. Molecular imaging of pancreatic cancer in an animal model using targeted multifunctional nanoparticles. Gastroenterology. 2009; 136:1514-1525 e1512.

5. Neesse A, Hahnenkamp A, Griesmann H, Buchholz M, Hahn SA, Maghnouj A, Fendrich V, Ring J, Sipos B, Tuveson DA, Bremer C, Gress TM, Michl P. Claudin-4targeted optical imaging detects pancreatic cancer and its precursor lesions. Gut. 2013; 62:1034-1043.

6. Lee JH, Huh YM, Jun YW, Seo JW, Jang JT, Song HT, Kim S, Cho EJ, Yoon HG, Suh JS, Cheon J. Artificially engineered magnetic nanoparticles for ultra-sensitive molecular imaging. Nature medicine. 2007; 13:95-99.

7. Kaushal S, McElroy MK, Luiken GA, Talamini MA, Moossa AR, Hoffman RM, Bouvet M. Fluorophore- conjugated anti-CEA antibody for the intraoperative imaging of pancreatic and colorectal cancer. Journal of gastrointestinal surgery. 2008; 12:1938-1950.

8. McElroy M, Kaushal S, Luiken GA, Talamini MA, Moossa AR, Hoffman RM, Bouvet M. Imaging of primary and metastatic pancreatic cancer using a fluorophore-conjugated anti-CA19-9 antibody for surgical navigation. World journal of surgery. 2008; 32:1057-1066.

9. Park JY, Hiroshima Y, Lee JY, Maawy AA, Hoffman RM, Bouvet M. MUC1 selectively targets human pancreatic cancer in orthotopic nude mouse models. PloS one. 2015; 10:e0122100.

10. Pollak M. Insulin and insulin-like growth factor signalling in neoplasia. Nat Rev Cancer. 2008; 8:915-928.

11. Hakam A, Fang Q, Karl R, Coppola D. Coexpression of IGF-1R and c-Src proteins in human pancreatic ductal adenocarcinoma. Dig Dis Sci. 2003; 48:1972-1978.

12. Bergmann U, Funatomi H, Yokoyama M, Beger HG, Korc M. Insulin-like growth factor I overexpression in human pancreatic cancer: evidence for autocrine and paracrine roles. Cancer Res. 1995; 55:2007-2011.

13. Pollak MN, Schernhammer ES, Hankinson SE. Insulinlike growth factors and neoplasia. Nat Rev Cancer. 2004; 4:505-518.

14. Maloney EK, McLaughlin JL, Dagdigian NE, Garrett LM, Connors KM, Zhou XM, Blattler WA, Chittenden T, Singh R. An anti-insulin-like growth factor I receptor antibody that is a potent inhibitor of cancer cell proliferation. Cancer Res. 2003; 63:5073-5083.

15. Kurzrock R, Patnaik A, Aisner J, Warren T, Leong S, Benjamin R, Eckhardt SG, Eid JE, Greig G, Habben K, McCarthy CD, Gore L. A phase I study of weekly R1507, a human monoclonal antibody insulin-like growth factor-I receptor antagonist, in patients with advanced solid tumors. Clin Cancer Res. 2010; 16:2458-2465.

16. Zhang H, Zeng X, Li Q, Gaillard-Kelly M, Wagner CR, Yee D. Fluorescent tumour imaging of type I IGF receptor in vivo: comparison of antibody-conjugated quantum dots and small-molecule fluorophore. British journal of cancer. 2009; 101:71-79.

17. Nakai $Y$, Isayama H, Shinoura S, Iwashita T, Samarasena JB, Chang KJ, Koike K. Confocal laser endomicroscopy in gastrointestinal and pancreatobiliary diseases. Dig Endosc. 2014; 26 Suppl 1:86-94.

18. Becker V, Wallace MB, Fockens P, von Delius S, Woodward TA, Raimondo M, Voermans RP, Meining A. Needle-based confocal endomicroscopy for in vivo histology of intra-abdominal organs: first results in a porcine model (with videos). Gastrointestinal Endoscopy. 2010; 71:1260-1266.

19. Metildi CA, Kaushal S, Lee C, Hardamon CR, Snyder CS, Luiken GA, Talamini MA, Hoffman RM, Bouvet M. An LED light source and novel fluorophore combinations improve fluorescence laparoscopic detection of metastatic 
pancreatic cancer in orthotopic mouse models. Journal of the American College of Surgeons. 2012; 214:997-1007 e1002.

20. Yelamali A, Mansard MJ, Dama R, Rebela P, Rao GV, Reddy DN. Intraoperative pancreatoscopy with narrow band imaging: a novel method for assessment of resection margins in case of intraductal papillary mucinous neoplasm. Surgical endoscopy. 2012; 26:3682-3685.

21. Konda VJ, Meining A, Jamil LH, Giovannini M, Hwang JH, Wallace MB, Chang KJ, Siddiqui UD, Hart J, Lo SK, Saunders MD, Aslanian HR, Wroblewski K, Waxman I. A pilot study of in vivo identification of pancreatic cystic neoplasms with needle-based confocal laser endomicroscopy under endosonographic guidance. Endoscopy. 2013; 45:1006-1013.

22. Metildi CA, Kaushal S, Pu M, Messer KA, Luiken GA, Moossa AR, Hoffman RM, Bouvet M. Fluorescenceguided surgery with a fluorophore-conjugated antibody to carcinoembryonic antigen (CEA), that highlights the tumor, improves surgical resection and increases survival in orthotopic mouse models of human pancreatic cancer. Annals of Surgical Oncology. 2014; 21:1405-1411.

23. Zhang Y, Cai W. Molecular imaging of insulin-like growth factor 1 receptor in cancer. Am J Nucl Med Mol Imaging. 2012; 2:248-259.

24. Maawy AA, Hiroshima Y, Kaushal S, Luiken GA, Hoffman RM, Bouvet M. Comparison of a chimeric anticarcinoembryonic antigen antibody conjugated with visible or near-infrared fluorescent dyes for imaging pancreatic cancer in orthotopic nude mouse models. Journal of biomedical optics. 2013; 18:126016.

25. Kobayashi H, Longmire MR, Ogawa M, Choyke PL. Rational chemical design of the next generation of molecular imaging probes based on physics and biology: mixing modalities, colors and signals. Chem Soc Rev. 2011; 40:4626-4648.

26. Kobayashi H, Ogawa M, Alford R, Choyke PL, Urano $\mathrm{Y}$. New strategies for fluorescent probe design in medical diagnostic imaging. Chem Rev. 2010; 110:2620-2640.

27. Blagosklonny MV. Treatment with inhibitors of caspases, that are substrates of drug transporters, selectively permits chemotherapy-induced apoptosis in multidrugresistant cells but protects normal cells. Leukemia. 2001; 15:936-941.

28. Blagosklonny MV. Matching targets for selective cancer therapy. Drug Discov Today. 2003; 8:1104-1107.

29. Blagosklonny MV. Tissue-selective therapy of cancer. British journal of cancer. 2003; 89:1147-1151.

30. Blagosklonny MV. Teratogens as anti-cancer drugs. Cell Cycle. 2005; 4:1518-1521.
31. Blagosklonny MV. How cancer could be cured by 2015 . Cell Cycle. 2005; 4:269-278.

32. Blagosklonny MV. Target for cancer therapy: proliferating cells or stem cells. Leukemia. 2006; 20:385-391.

33. Tan MH, Nowak NJ, Loor R, Ochi H, Sandberg AA, Lopez C, Pickren JW, Berjian R, Douglass HO, Jr., Chu TM. Characterization of a new primary human pancreatic tumor line. Cancer investigation. 1986; 4:15-23.

34. Lieber M, Mazzetta J, Nelson-Rees W, Kaplan M, Todaro G. Establishment of a continuous tumor-cell line (panc1) from a human carcinoma of the exocrine pancreas. International journal of cancer Journal international du cancer. $1975 ; 15: 741-747$.

35. Uchugonova A, Zhao M, Weinigel M, Zhang Y, Bouvet M, Hoffman RM, Konig K. Multiphoton tomography visualizes collagen fibers in the tumor microenvironment that maintain cancer-cell anchorage and shape. Journal of cellular biochemistry. 2013; 114:99-102.

36. Yang M, Jiang P, Hoffman RM. Whole-body subcellular multicolor imaging of tumor-host interaction and drug response in real time. Cancer research. 2007; 67:5195-5200.

37. Bouvet M, Wang J, Nardin SR, Nassirpour R, Yang M, Baranov E, Jiang P, Moossa AR, Hoffman RM. Real-time optical imaging of primary tumor growth and multiple metastatic events in a pancreatic cancer orthotopic model. Cancer research. 2002; 62:1534-1540.

38. Bouvet M, Yang M, Nardin S, Wang X, Jiang P, Baranov E, Moossa AR, Hoffman RM. Chronologically-specific metastatic targeting of human pancreatic tumors in orthotopic models. Clinical \& experimental metastasis. 2000; 18:213-218.

39. Fu X, Guadagni F, Hoffman RM. A metastatic nudemouse model of human pancreatic cancer constructed orthotopically with histologically intact patient specimens. Proceedings of the National Academy of Sciences of the United States of America. 1992; 89:5645-5649.

40. Furukawa T, Kubota T, Watanabe M, Kitajima M, Hoffman RM. A novel "patient-like" treatment model of human pancreatic cancer constructed using orthotopic transplantation of histologically intact human tumor tissue in nude mice. Cancer research. 1993; 53:3070-3072.

41. Yamauchi $\mathrm{K}$, Yang $\mathrm{M}$, Jiang $\mathrm{P}, \mathrm{Xu} \mathrm{M}$, Yamamoto $\mathrm{N}$, Tsuchiya H, Tomita K, Moossa AR, Bouvet M, Hoffman RM. Development of real-time subcellular dynamic multicolor imaging of cancer-cell trafficking in live mice with a variable-magnification whole-mouse imaging system. Cancer research. 2006; 66:4208-4214.

42. Alencar H, Mahmood U, Kawano Y, Hirata T, Weissleder R. Novel multiwavelength microscopic scanner for mouse imaging. Neoplasia. 2005; 7:977-983. 